\title{
Pierre-René Lemonnier, La matrone chinoise ou l'épreuve ridicule, comédie (1765)
}

\section{Paola Sosso}

\section{(2) OpenEdition}

1 Journals

\section{Edizione digitale}

URL: http://journals.openedition.org/studifrancesi/36232

DOI: 10.4000/studifrancesi.36232

ISSN: 2421-5856

\section{Editore}

Rosenberg \& Sellier

\section{Edizione cartacea}

Data di pubblicazione: 1 juillet 2005

Paginazione: 171

ISSN: 0039-2944

\section{Notizia bibliografica digitale}

Paola Sosso, «Pierre-René Lemonnier, La matrone chinoise ou l'épreuve ridicule, comédie (1765)», Studi Francesi [Online], 145 (XLIX | I) | 2005, online dal 30 novembre 2015, consultato il 18 avril 2021. URL: http://journals.openedition.org/studifrancesi/36232 ; DOI: https://doi.org/10.4000/studifrancesi. 36232

Questo documento è stato generato automaticamente il 18 avril 2021.

\section{(c) $(1) \ominus$}

Studi Francesi è distribuita con Licenza Creative Commons Attribuzione - Non commerciale - Non opere derivate 4.0 Internazionale. 


\section{Pierre-René Lemonnier, La matrone chinoise ou l'épreuve ridicule, comédie (1765)}

Paola Sosso

\section{NOTIZIA}

PIERRE-RENÉ LEMONNIER, La matrone chinoise ou l'épreuve ridicule, comédie (1765), édition critique publiée avec une introduction, des notes et une documentation thématique par LING-LING SHEU. Préface de Frederic DelofFre, Exeter, University of Exeter Press, 2003, pp. 116.

1 Si tratta dell'edizione critica di una commedia in due atti «en vers libres» portata in scena per la prima volta a Parigi nel 1765 e mai più ripubblicata fino ad oggi. Il tema della matrona di Efeso di Petronio, ripreso in questa pièce, fu riadattato da vari scrittori lungo i secoli, fra i quali, come è noto, La Fontaine. Nel XVIII secolo il Père Du Halde pubblicò un racconto cinese sul tema universale dell'infedeltà delle donne nella sua Description de la Chine del 1735. Ispirandosi a Zadig di Voltaire, che si era a sua volta ispirato alla versione di Du Halde, e avendo presente il racconto di Petronio, Lemonnier fu il primo ad utilizzare i dati della versione cinese riportata da Du Halde (e ripresa nel 1755 da Fréron nel Journal étranger) per portare sulle scene una nuova versione della matrona di Efeso. Lemonnier innova in modo originale il conte cinese: grazie a un travestimento, l'amante e il marito divengono nella sua commedia la stessa persona, in modo tale che l'infedeltà della moglie risulti solo apparente. Interessante, a proposito dell'evoluzione del tema della matrona d'Efeso, lo schema proposto dal curatore (pp. 16-17) in cui si delineano in modo chiaro le varianti di un tema diversamente modellato col passare dei secoli. Sull'autore della commedia ben poco si sa, al di là di ciò che riportano i grandi dizionari biografici del XIX secolo. Questo "célèbre inconnu" nacque a Parigi nel 1731, fu segretario del marchese Maillebois, poi a Metz, amministratore per le spese militari. Morì a Metz nel 1796. Lemonnier fu un autore drammatico che godette 
di un certo successo al Théâtre italien, anche se dai documenti in nostro possesso pare che La matrone chinoise non abbia incontrato i gusti del pubblico. Chiara e precisa, l'introduzione al testo offre tra l'altro un significativo studio della versificazione di questa pièce, di cui rimangono solo due esemplari, uno alla Biblioteca dell'Arsenale, l'altro alla biblioteca Reale di Bruxelles. La Documentation thématique riproduce, infine, le versioni anteriori a Lemonnier, quella di Petronio, quella di Du Halde, quella di Fréron e quella di Voltaire, oltre ad alcuni elementi relativi alla fonte cinese. Una bibliografia essenziale chiude il volume. 